\title{
Factors Influencing Workplace Bullying among Employees in a Private Education Institution
}

\section{Suzanne Jana \& Siti Noormi Alias}

To Link this Article: http://dx.doi.org/10.6007/IJARBSS/v11-i12/11828

DOI:10.6007/IJARBSS/v11-i12/11828

Received: 16 October 2021, Revised: 20 November 2021, Accepted: 04 December 2021

Published Online: 14 December 2021

In-Text Citation: (Jana \& Alias, 2021)

To Cite this Article: Jana, S., \& Alias, S. N. (2021). Factors Influencing Workplace Bullying among Employees in a Private Education Institution. International Journal of Academic Research in Business and Social Sciences, 11(12), 899-909.

\section{Copyright: @ 2021 The Author(s)}

Published by Human Resource Management Academic Research Society (www.hrmars.com)

This article is published under the Creative Commons Attribution (CC BY 4.0) license. Anyone may reproduce, distribute, translate and create derivative works of this article (for both commercial and non0-commercial purposes), subject to full attribution to the original publication and authors. The full terms of this license may be seen at: http://creativecommons.org/licences/by/4.0/legalcode

Full Terms \& Conditions of access and use can be found at http://hrmars.com/index.php/pages/detail/publication-ethics 


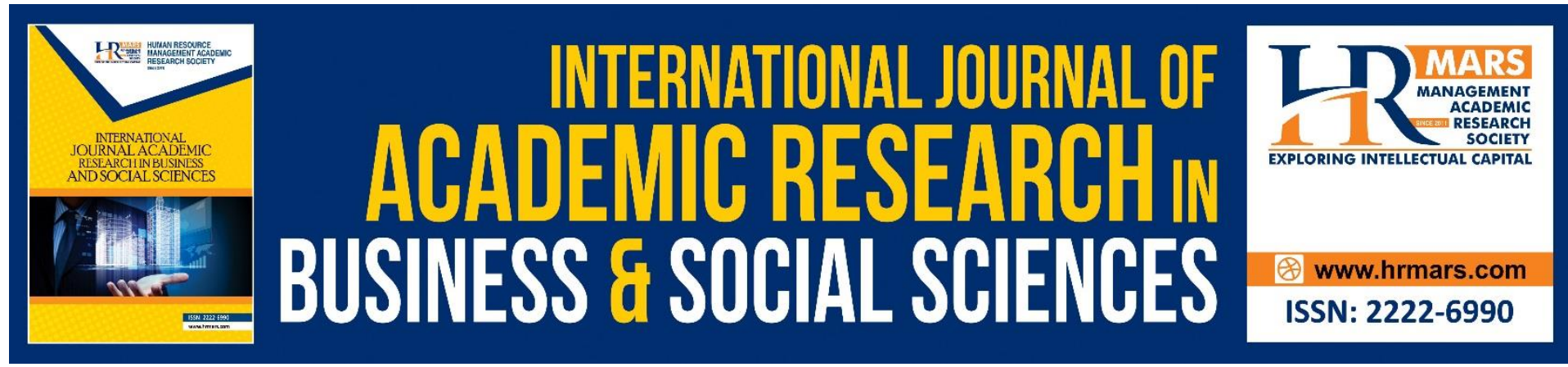

\title{
Factors Influencing Workplace Bullying among Employees in a Private Education Institution
}

\author{
Suzanne Jana \& Siti Noormi Alias \\ Faculty of Educational Studies, Universiti Putra Malaysia, 43400 UPM Serdang, Selangor, \\ Malaysia
}

\begin{abstract}
Background - Workplace bullying can happen in any organizations. This type of bullying happens among employees and employers. Bullying at workplace is considered as one of the worst acts, including negative acts like verbal aggressions, isolation and naming, which can cause life destruction to an individual. Purpose - The purpose of the study was to determine the level of workplace bullying among employees in a private education institution. Hence, three independent variables were selected based on theories on previous studies that are abusive supervision, hostile working environment and workplace ostracism. Design - The design of this study was a quantitative method in which sixty-six respondents from support staffs in the selected private education institution participated in a survey. The method used to distribute the questionnaire was Google online survey forms. The actual respondents were 80 participants, however, only 66 respondents successfully participated in the workplace bullying survey. Findings - Based on the finding on the selected three independent variables, namely, abusive supervision, hostile working environment and workplace ostracism, it showed that abusive supervision and hostile working environment had $p$-value less than 0.05 which contributed to the main dependent variable that is workplace bullying. Conclusion Several studies have demonstrated that workplace bullying, confirmed by these findings, has far-reaching effects on the entire society. The high rate of this type of workplace bullying, such as in this study, should motivate researchers to examine workplace bullying in general, and drive practitioners to do so as well.

Keywords: Workplace Bullying, Private Education Institution, Abusive Supervision, Hostile Working Environment, Workplace Ostracism
\end{abstract}

\section{Introduction}

In the early 1990s, the term 'bullying in the workplace' was coined to describe a pattern of relentless violence, crime, fear, incivility, insult, misuse of power, and severe consequences for victims in Scandinavia (Paull \& Omari, 2015). Workplace bullying is repeated harm to a person as well as abuse which may include negative acts such as demeaning, berating, or telling someone that they are useless or incompetent (Akella, 2016).

Devonish (2017) reported that "bullying in the workplace has been recognized as a serious problem in organizations in both developed and developing countries, resulting in significant social and psychological problems". The research would, therefore, be performed at one of 
the private institutions of education. As indicated by Ahmad et al (2017), academics play a vital part in the conveyance of higher education in a country. In addition, scholars are not only reliable in educating and training the future workforce, but also in contributing to the progress of society through their study (Ahmad et al., 2017). The prevalence of workplace bullying in academic environments, however, can potentially affect the learning of students and decrease the level of intellectual performances in higher education (Keashly \& Neuman, 2010; McKay et al., 2008).

\section{Objectives}

To determine the level of workplace bullying among employees in a private education institution.

i. To determine the level of abusive supervision, hostile working environment and workplace ostracism among employees in a private education institution.

ii. To determine the relationship between abusive supervision, hostile working environment and workplace ostracism towards workplace bullying among employees in a private education institution.

iii. To determine the factors influencing the workplace bullying among employees in a private education institution.

\section{Concept of Dependent Variables Workplace Bullying}

Devonish (2017) quoted an example from Rayner and Hoel (1997), there are several previous studies that have described workplace bullying according to its actions. For the sake of further clarification, the terms 'belittling one's profession and belittling one's opinion' are used, as well as 'refusing to grant one credit when it is due' and terrorizing one', as well as 'terrorizing', and failure to give due credit'.

Hypothesis 1: There is the main factor in workplace bullying among employees in a private education institution.

\section{Concept of Independent Variables \\ Abusive Supervision}

Most leadership studies have examined the actions of successful leaders, but not all have investigated the potential motives behind them (Kim et al., 2016). Formally, openly berating, insulting, and harassing the troops is known as "abusive supervision" (Aryee et al., 2008). Despite, few studies have investigated the implications of these types of leader behaviours on debilitating workers' abilities to share their knowledge (Kim et al., 2016).

Hypothesis 2: There is a positive and significant relationship between abusive supervision and workplace bullying among employees in a private education institution.

\section{Hostile Working Environment}

Hostile working environment is defined as "unwelcoming and unwanted conduct that causes the employee to feel anxious, worried, or frightened" (The Legal Dictionary, 2017a, 2017b, 2017c). A hostile atmosphere may be created by various acts, such as teasing, swearing, acts of in sub-ordinance, nicknames, and demands for sexual favours, including such as touches, stares, attention, harassment, and sexual abuse. Successor partners, in addition, the offended party can also be colleagues, customers, clients, and/customers (Walker, 2018). 
Hypothesis 3: There is a positive and significant relationship between hostile working environment and workplace bullying in a private education institution.

\section{Workplace Ostracism}

According to Chung (2015), ostracism is prevalent in daily human life and can manifest itself in both silence and total avoidance (Ferris et al., 2008). Additionally, ostracism is the absence of cooperation, e.g. not perceiving, including, or selecting, or even initiating cooperation, cooperation, with another person or group (Chung, 2015). On the other hand, Chung (2015) stated that the treatment of one gives one receives will depend on whether one has reacted poorly in the previous encounter with another person, regardless of their feelings about this (Robinson et al., 2013).

Hypothesis 4: There is a positive and significant relationship between workplace ostracism and workplace bullying in a private education institution.

\section{Design of Study}

The research methodology for this study is a quantitative research. The study is primarily designed to find out, from a cross-section of employees from an organization, the perceptions about workplace bullying. The employees were from different departments and hold different positions in the organization level. In order to collect information, there was a specific group participating in the study of workplace bullying. It is proposed to select a sample from employees as sampling strategy. The questionnaires were distributed through email. The participants were requested to respond within one week after the distribution of questionnaire was completed. Before the study was conducted, the employees were informed through supporting letter of the purpose of the study. It explained the objectives and relevance of the study by assuring their information would be retained as confidential and they could decide whether to participate or not in the study.

\section{Instrument}

In the advent of technology, the online questionnaire is a proper medium to collect data from the respondents. The questionnaires were distributed to the employees via email and it helped to save time and financial resources.

To measure the perceptions towards workplace bullying, it is crucial to identify what are the perceptions of the employees on the issue studied by using attitudinal scales. Attitudinal scales is a "scales designed to measure attitudes towards an issue". There are three types of scale in social sciences, namely, Likert-scale, Thurston-scale and Guttman-scale (Kumar, 2014).

Likert-scale was used in this analysis to assess workplace bullying. Likert-scale known as the 'summated rating scale' is one of the attitudinal scales designed to assess attitudes. This scale implies that each statement or object has the same "value," "importance" or "weight" in terms of demonstrating an attitude towards the issue in questions (Kumar, 2014). The Likert-scale was rated from a scale of 1 to 5 . The respondent was requested to rate the scale of 1 'Strongly disagree', 2 'Disagree', 3 'Neutral', 4 'Agree' and 5 'Strongly agree'. The result was determined by Cronbach's alpha with the value of 0.7 . The items were developed based on previous studies. 


\section{Section A}

In this section, the information regarding the demographic variables such as marital status, level of education, employee status, number of employees and level of employment was obtained.

\section{Section B}

Workplace bullying: Among three factors of workplace bullying, person-related bullying was selected to be included in the questionnaire. A twelve-item scale developed by Einarsen et al. (2009) was used to measure person-related bullying. The response options ranged from 1 ('strongly disagree') to 5 ('strongly agree'). Cronbach's alpha for this measure was 0.978 .

\section{Section C}

Abusive supervision: A 15-item scale developed by Tepper (2000) was used to measure abusive supervision. The response options of the measure ranged from 1 'strongly disagree' to 5 'strongly agree'. The Cronbach's alpha for this scale was 0.974.

\section{Section D}

Hostile working environment: A six-item scale developed by Adams and John (1997) was used to measure hostile attribution bias. The response options of the measure ranged from 1 'strongly disagree' to 5 'strongly agree'. The Cronbach's alpha for this scale was 0.901.

\section{Section E}

Workplace ostracism: A ten-item scale developed by Ferris et al. (2008) was used to measure workplace ostracism. Response options ranged from 1 'strongly disagree' to 5 'strongly agree'. Cronbach's alpha for this measure was 0.975 .

\section{Reliability Analysis (Cronbach Alpha)}

\section{Table 1 Pilot test on each of variables}

\begin{tabular}{lll}
\hline Variables & No of Items & Cronbach's Alpha \\
\hline $\begin{array}{l}\text { Dependent Variable } \\
\text { Workplace Bullying }\end{array}$ & 12 & 0.968 \\
& & \\
Independent Variables & 15 & 0.938 \\
Abusive Supervision & 6 & 0.883 \\
Hostile Working Environment & 10 & 0.976 \\
Workplace Ostracism & & \\
\hline
\end{tabular}

\section{Population}

The research population for the study was employees in a private education institution. The two small institutions have a total population of approximately 80 employees in an organization. The employees consisted of individuals who hold different positions in the organization. There are different levels of positions held by employees, namely, management level, executive level, and non-executive level. However, there are varieties of departments within an organization with different functions. Each department is divided into business development, academic and non-academic. Participants were asked about workplace bullying. 
In this study, the target population supports staffs were the administrative executives and administrative assistants. Both positions held different titles and job descriptions in an organization.

\section{Sampling}

To decide on the sample size, Krejie and Morgan were used to determine the number of samples to be respondents in this study. The sample size suggested was 66 .

\section{Data Collection}

Before distributing the questionnaires, the researcher sent emails to the Human Resource personnel in the selected private education institutions and made phone calls to communicate clearly the objective of this study. However, there were only two private education institutions responded and distributed the link to the selected sample size via email.

The questionnaires were distributed online by using Google survey form. All 66 respondents were mailed the link to the Google survey form. About two weeks, soft reminder were sent in order to complete the survey form within the timeline.

\section{Data Analysis}

The research aimed to measure workplace bullying among private education institution. There were two sections of the questionnaires in this study, namely, Section $A$ and B. Section A was about demographic information that was the respondents' individual information. Section B was the items about the workplace bullying. Section B consisted of all the items connected to the independent and dependent variables.

Data were examined via Statistical Package for the Social Sciences (SPSS) software. The descriptive statistical analysis was used to screen data, identify potential outliers, and characterize variances at the group or case level.

Each of the objectives was analysed accordingly to obtain data as the table below; 
Table 2. Data Analysis

\begin{tabular}{|l|l|}
\hline Objectives & Analysis data \\
\hline $\begin{array}{l}\text { To determine the level of the workplace } \\
\text { bullying among employees in a private } \\
\text { education institution. }\end{array}$ & $\begin{array}{l}\text { Descriptive analysis } \\
\text { Frequency, Percentage, Means and } \\
\text { Standard deviation }\end{array}$ \\
\hline $\begin{array}{l}\text { To determine the level of abusive } \\
\text { supervision, hostile working } \\
\text { environment and workplace ostracism } \\
\text { among employees in a private } \\
\text { education institution. }\end{array}$ & $\begin{array}{l}\text { Descriptive analysis } \\
\text { Frequency, Percentage, Means and } \\
\text { Standard deviation }\end{array}$ \\
\hline $\begin{array}{l}\text { To determine the relationship between } \\
\text { abusive supervision, hostile working } \\
\text { environment and workplace ostracism } \\
\text { towards workplace bullying among } \\
\text { employees in a private education } \\
\text { institution. }\end{array}$ & PPMCC (Pearson product-moment \\
\hline $\begin{array}{l}\text { To determine the factors influencing } \\
\text { the workplace bullying among } \\
\text { employees in a private education } \\
\text { institution. }\end{array}$ & Multiple linear regression \\
\hline
\end{tabular}

\section{Findings \& Discussion}

\section{Level of Dependant Variable}

Table 3. Level of Workplace Bullying

\begin{tabular}{lllll}
\hline Variables & $f$ & $\%$ & Mean & SD \\
\hline Workplace bullying & & & 3.16 & 1.140 \\
Low $(1.00-2.339)$ & 21 & 31.8 & & \\
Medium $(2.34-3.649)$ & 18 & 27.3 & & \\
High (3.66 - 5.00) & 27 & 40.9 & & \\
\hline
\end{tabular}

$27.3 \%$ of respondents in this study indicated a medium level of workplace bullying, $31.8 \%$ indicated a low level of workplace bullying and $40.9 \%$ indicated a high level of workplace bullying. In conclusion, from the table below, it clearly indicated the existence of workplace bullying even though half of the respondents do agree on the workplace bullying under control. 
INTERNATIONAL JOURNAL OF ACADEMIC RESEARCH IN BUSINESS AND SOCIAL SCIENCES

Vol. 11, No. 12, 2021, E-ISSN: 2222-6990 ๑ 2021 HRMARS

Level of Independent Variables

Table 4. Level of abusive supervision, hostile working environment and workplace ostracism

\begin{tabular}{lllll}
\hline Variables & $f$ & $\%$ & Mean & SD \\
\hline Abusive supervision & & & 2.49 & 1.177 \\
Low (1.00-2.339) & 38 & 57.6 & & \\
Medium (2.34-3.649) & 15 & 22.7 & & \\
High (3.66-5.00) & 13 & 19.7 & & \\
Hostile working environment & & & 3.32 & .920 \\
Low (1.00-2.339) & 11 & 16.7 & & \\
Medium (2.34-3.649) & 34 & 51.5 & & \\
High (3.66-5.00) & 21 & 31.8 & & \\
& & & & \\
Workplace ostracism & & & & \\
Low (1.00-2.339) & 46 & 69.7 & & \\
Medium (2.34-3.649) & 8 & 12.1 & & \\
High (3.66-5.00) & 12 & 18.2 & & \\
\hline
\end{tabular}

\section{Abusive Supervision}

The categorization of abusive supervision revealed that most of the respondents (57.6\%) reported having a low level of abusive supervision, $22.7 \%$ having medium abusive supervision followed by $19.7 \%$ for high-level of abusive supervision. The values of the mean and standard deviation of abusive supervision were 2.49 and 1.177 respectively.

\section{Hostile Working Environment}

The categorization of hostile working environment revealed that most of the respondents (51.5\%) reported having a moderate level of hostile working environment, $31.8 \%$ having a high level of hostile working environment followed by $16.7 \%$ of respondents having a low level of the hostile working environment. The values of the mean and standard deviation of the hostile working environment were 3.32 and 0.920 respectively.

\section{Workplace Ostracism}

The categorization of workplace ostracism revealed that most respondents (69.7\%) reported having a low level of workplace ostracism, $18.2 \%$ having a high level of workplace ostracism followed by $12.1 \%$ having a moderate level of workplace ostracism.

PPMCC (PEARSON PRODUCT-MOMENT CORRELATION COEFFICIENT) Table 5. PPMCC (Pearson Product-Moment Correlation Coefficient)

\begin{tabular}{lllllll}
\hline & $\mathrm{Y}$ & $\mathrm{X}_{1}$ & $\mathrm{X}_{2}$ & $\mathrm{X}_{3}$ & Mean & $\mathrm{SD}$ \\
\hline $\mathrm{Y}$ & 1 & $.641^{* *}$ & $.575^{* *}$ & $.536^{* *}$ & 3.16 & 1.140 \\
$\mathrm{X}_{1}$ & $.641^{* *}$ & 1 & $.585^{* *}$ & $.806^{* *}$ & 2.49 & 1.177 \\
$\mathrm{X}_{2}$ & $.575^{* *}$ & $.585^{* *}$ & 1 & $.462^{* *}$ & 3.32 & .920 \\
$\mathrm{X}_{3}$ & $.536^{* *}$ & $.806^{* *}$ & $.462^{* *}$ & 1 & 2.21 & 1.211 \\
\hline \multicolumn{5}{r}{. Correlation is significant at the 0.01 level (2-tailed) }
\end{tabular}




\section{Correlation Analysis between Abusive Supervision and Workplace Bullying}

Table 5 illustrates the result of correlation analysis between abusive supervision and workplace bullying. The nature of the relationship between the two variables in terms of direction is positive as Pearson correlation value indicates 0.641 and the strength of relationship based on Guildford Rule of Thumb is a moderate relationship between abusive supervision and workplace bullying.

$\mathrm{H}_{1}$ : Therefore, there is a significant and moderate relationship between abusive supervision which leads to workplace bullying.

\section{Correlation Analysis between Hostile Working Environment and Workplace Bullying}

Table 5 illustrates the result of correlation analysis between hostile working environment and workplace bullying. The nature of the relationship between the two variables in terms of direction is positive as Pearson correlation value indicates 0.575 and the strength of relationship based on Guildford Rule of Thumb is a moderate relationship between hostile working environment and workplace bullying.

$\mathrm{H}_{2}$ : Therefore, there is a significant and moderate relationship between hostile working environment and workplace bullying.

\section{Correlation Analysis between Workplace Ostracism and Workplace Bullying}

Table 4.3 illustrates the result of correlation analysis between workplace ostracism and workplace bullying. The nature of the relationship between the two variables in terms of direction is positive as Pearson correlation value indicates 0.536 and the strength of relationship based on Guildford Rule of Thumb is a moderate relationship between workplace ostracism and workplace bullying.

$\mathrm{H}_{3}$ : Therefore, there is a significant and moderate relationship between workplace ostracism and workplace bullying.

To summarize, when employees experienced moderate levels of abusive supervision, hostile working environment, and workplace ostracism, they were still under control of workplace bullying compare to other employees who experienced a high level of abusive supervision, hostile working environment

\section{Discussion}

Abusive supervision and hostile working environment are the best factors in explaining workplace bullying among support staffs in selected private organizations. The findings of this study stated that abusive supervision and the hostile working environment caused workplace bullying.

According to a recent study, bullying has also been found to be associated with ranking in the workplace (Ahmad et al, 2017). Downward bullying is known to be prevalent in many cases of these offences (Branch et al., 2007 and Thomas, 2005). For an example, Rayner (1997) found that supervisors and managers executed more than $70 \%$ of workplace bullying cases. While downward bullying was more common, workplace bullying could be seen at different levels, such as subordinates bullying their superiors (Branch et al., 2007).

In addition, workplace bullying is often used as a mean to damage the overall academic hierarchies, for example, mean-spirited academic cultures are created, (Comer et al., 2012; Gumbus and Vega, 2010) and workplace quality is harmed (Ahmad et al., 2017). Giorgi (2012) conducted a study in a large Italian university and concluded that workplace bullying could potentially spread to a toxic working environment. Thus, the study has 
supported the damaging effects of workplace bullying on the academic work environment and academics' health.

\section{Implication}

\section{For Organization}

Workplace bullying can either be intentional or unintentional, and should be anticipated, leading to the conclusion that any several workplace health concerns may be rendered harmless by not being managed properly.

\section{On Employee Behaviour}

Workplace bullying can lead to reduced productivity of employees. With a myriad of cultural issues in the workplace, employers must seriously consider adopting internal organizational strategies to address the problem of workplace bullying.

\section{Employee Health}

Similarly, the psychological effects of hostile work conditions on employees vary widely but are often detrimental to mental health. Employees can become terrible and less productive, unbalanced moods, emotional distress, and lack of focus (Cortina, 2008, p. 56).

\section{Recommendation}

Practice

Researchers and practitioners should propose and enforce anti-bullying strategies aimed at producing 'zero-resilience' for harassment, increasing understanding of what is involved and clarifying what is meant by 'acceptable' work behaviours (European Agency, 2002; Hubert 2003; Mathieson et al., 2006; Richards \& Daley, 2003; Vartia et al., 2003).

\section{Future Research}

Future studies on workplace bullying should be longitudinal work, conducted in diverse geographical and occupational settings, incorporate other factors and conducted either quantitatively or qualitatively in order to explore more the meaning of workplace bullying in the Malaysian context.

\section{Corresponding Author}

Suzanne Jana

Faculty of Educational Studies, Universiti Putra Malaysia, 43400 UPM Serdang, Selangor

Email: suzannejana.91@gmail.com

\section{References}

\section{Journal Article}

Ahmad, S., Kalim, R., \& Kaleem, A. (2017). Academics' perceptions of bullying at work: insights from Pakistan. International Journal of Educational Management, 31(2), 204-220. doi:10.1108/ijem-10-2015-0141

Aryee, S., Sun, L. Y., Chen, Z. X., \& Debrah, Y. A. (2008), Abusive supervision and contextual performance: the mediating role of emotional exhaustion and the moderating role of workunit structure, Management and Organization Review, 4(3), 393-411.

Akella, D. (2016). Workplace Bullying. SAGE Open, 6(1), 215824401662939. doi:10.1177/2158244016629394 
Branch, S., Ramsay, S., \& Barker, M. (2007), Managers in the firing line: contributing factors to workplace bullying by staff - an interview study, Journal of Management and Organization, 13(3), 264-281.

Chung, Y. W. (2015). The mediating effects of organizational conflict on the relationships between workplace ostracism with in-role behavior and organizational citizenship behavior. International Journal of Conflict Management, 26(4), 366-385. doi:10.1108/ijcma-01-2014-0001

D'Cruz, P., Paull, M., Omari, M., \& Guneri-Cangarli, B. (2016). Target experiences of workplace bullying: insights from Australia, India and Turkey. Employee Relations, 38(5), 805823. http://dx.doi.org/10.1108/er-06-2015-0116

Devonish, D. (2017). Dangers of workplace bullying: evidence from the Caribbean. Journal Of Aggression, Conflict And Peace Research, 9(1), 69-80. http://dx.doi.org/10.1108/jacpr-05-2016-0228

Einarsen, S., Hoel, H., \& Notelaers, G. (2009), Measuring exposure to bullying and harassment at work: validity, factor structure and psychometric properties of the negative acts questionnaire-revised, Work \& Stress, 23(1), 24-44.

Ferris, D. L., Brown, D. J., Berry, J. W., \& Lian, H. (2008), The development and validation of the workplace ostracism scale, Journal of Applied Psychology, 93(6), 1348-1366.

Giorgi, G. (2012), Workplace bullying in academia creates a negative work environment. an Italian Study, Employee Responsibilities and Rights Journal, 24(4), 261-275, doi: 10.1007/s10672-012-9193-7.

Gumbus, A., \& Meglich, P. (2012), Lean and mean: workplace culture and the prevention of workplace bullying, The Journal of Applied Business and Economics, 13(5), 11-20, doi: $10.1177 / 107179190601200301$.

Keashly, L. (2010), A researcher speaks to ombudsmen about workplace bullying, Journal of the International Ombudsman Association, 3(2), 10-23.

Robinson, S. L., O'Reilly, J., \& Wang, W. (2013), Invisible at work: an integrated model of workplace ostracism, Journal of Management, 39(1), 203-231.

Kim, S. L., Lee, S., \& Yun, S. (2016). Abusive supervision, knowledge sharing, and individual factors. Journal of Managerial Psychology, 31(6), 1106-1120.

Tepper, B. J. (2000), Consequences of abusive supervision, Academy of Management Journal, 43(2), 178-190.

Book

Kumar, R. (2014). Research methodology (1st ed.). Los Angeles, Calif. [u.a.]: Sage Publ. 